\title{
Effects of short chain fatty acids on gut morphology and function
}

\author{
W Scheppach
}

\begin{abstract}
Short chain fatty acids (SCFAs) are the products of colonic bacterial degradation of unabsorbed starch and non-starch polysaccharide (fibre). They are important anions in the colonic lumen, affecting both colonocyte morphology and function. The three main acids (acetate, propionate, and butyrate) stimulate colonic sodium and fluid absorption and exert proliferative effects on the colonocyte. Experimental animal studies have shown that they promote adaptive responses to small intestinal resection and colonic anastomosis. Acetate increases colonic blood flow and enhances ileal motility. Butyrate has been shown to be the preferred energy substrate for the colonocyte and to be a potent differentiating agent in cell culture. Butyrate may also have a role in preventing certain types of colitis. A diet low in resistant starch and fibre, which will result in a low production of SCFAs in the colon, may explain the high occurrence of colonic disorders seen in the Western civilisation.
\end{abstract}

(Gut 1994; supplement 1: S35-S38)

Department of Medicine, University of Wurzburg, Germany

W Scheppach

Correspondence to: Dr Scheppach, Department Würzburg, Josef-SchneiderStrasse 2, D-97080 Würzburg, Germany. of Medicine, University of

There is evidence that epithelia lining the intestinal tract rely more on luminal than on vascular energy supply. In the fed state, luminal glutamine and glucose are the main fuels for small intestinal epithelial cells. ${ }^{1}$ During starvation, endogenous sources (glutamine from muscle catabolism, ketone bodies from hepatic ketogenesis) can meet the energy requirements of enterocytes through the

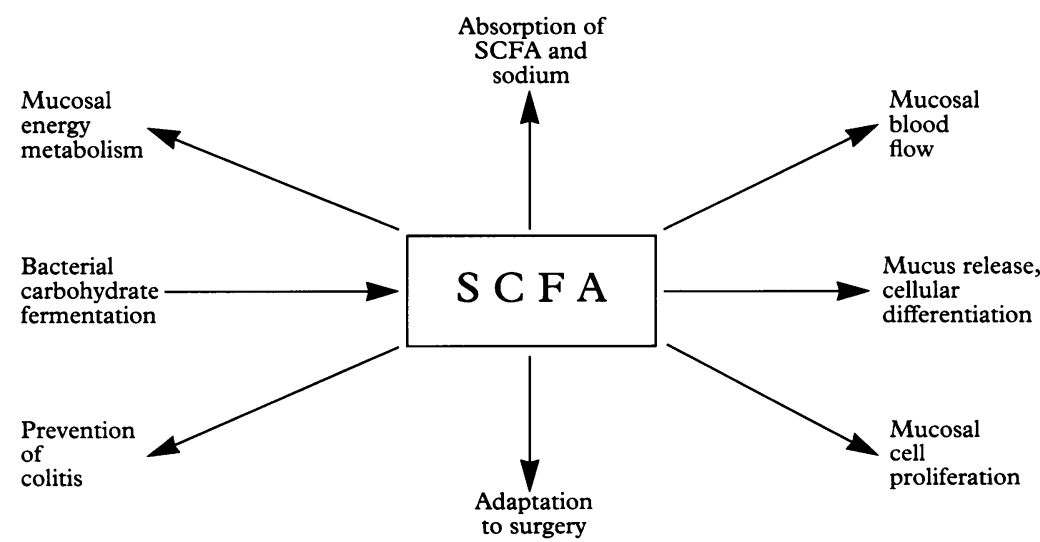

Effects of short chain fatty acids (SCFAs) on colonic morphology and function (facts and hypotheses). Their production during bacterial carbohydrate (starch, fibre) fermentation is well established. SCFAs are the preferred energy substrates of colonocytes, especially in the distal large bowel. Probably linked to this property, they affect a range of mucosal events (absorptive processes, blood flow, mucus release, cellular differentiation and proliferation). These effects of SCFAs are possibly clinically important (adaptation to postoperative conditions, prevention of colitis). vascular bed. ${ }^{2}$ The colonic epithelial cells are differently fuelled: short chain fatty acids (SCFAs) derived from bacterial carbohydrate (dietary fibre, starch) fermentation are important luminal substrates for colonocytes; of these, there is evidence that butyrate is the most important. ${ }^{3}$ In the starved colon, these substrates cannot easily be replaced by endogenous nutrients, except by the less abundant ketone bodies; diminished mucosal nutrition may therefore lead to mucosal atrophy, diminished absorption and, eventually, to colitis. ${ }^{4}$

This paper discusses the evidence that SCFAs are important anions in the colonic lumen that influence gut morphology and function. As outlined in the Figure they play an important part in stimulating colonic fluid and sodium absorption. They also affect colonic mucosal blood flow, ileal motility, caecal mucin secretion, colonocyte cellular differentiation, and mucosal cell proliferation. Linked to their role as important energy substrates of colonocytes they may favour adaptive responses to surgical interventions. There is evidence that they participate in the pathogenesis of colonic inflammatory conditions and they may even have a therapeutic role in some of these. The physiology of SCFAs as applied to some of these events will be discussed.

\section{Colonic absorption of SCFAs}

About $95-99 \%$ of SCFAs produced by bacterial fermentation are rapidly absorbed from the colonic lumen. Although the exact mechanism of SCFA absorption is not yet fully understood, the following experimental data have been obtained ${ }^{5-7}$ : (a) SCFA transport across the apical membrane is concentration dependent and shows no saturation kinetics; (b) non-ionic diffusion along the transcellular pathway seems most important; (c) SCFA absorption is coupled with $\mathrm{Na}^{+}$absorption, probably by $\mathrm{Na}^{+}-\mathrm{H}^{+}$exchange; (d) there are considerable segmental differences with regard to epithelial SCFA permeability ('leaky' epithelium in the proximal colon, 'tight', and aldosterone dependent epithelium in the distal colon).

By stimulating sodium and water absorption, SCFAs act as an anti-diarrhoeal agent. After right hemicolectomy, this effect is maintained by adaptation of the remaining left hemicolon; after subtotal or total colectomy, however, diarrhoea occurs as a consequence of impaired fermentation. ${ }^{8}$ Antibiotics have been shown to cause diarrhoea and, simultaneously, reduce faecal SCFA concentrations and SCFA production rates in vitro. ${ }^{9}$ Many cases of lactose intolerance are clinically inapparent 
because bacterial lactose fermentation reduces the osmotic load and generates SCFA, which are subsequently absorbed. Thus, SCFA absorption plays an important part in colonic carbohydrate and sodium salvage.

\section{Colonocyte metabolism of SCFAs}

The intact walls of the guinea pig caecum and upper colon were shown in vitro to metabolise ${ }^{14} \mathrm{C}$-butyrate to ketone bodies; the presence of acetate and propionate did not affect ketogenesis from butyrate. ${ }^{10}$ In suspensions of isolated epithelial cells from the human colon butyrate had a sparing effect on glucose and glutamine oxidation. On the other hand, labelling of butyrate showed that glucose or glutamine did not diminish the entry of fatty acid carbon into the citric acid cycle. The preference of colonocytes for butyrate as a fuel was more pronounced in the distal than the proximal colon. ${ }^{3}$ Isolated rat colonocytes responded to nutrient deprivation by a general reduction of oxidative metabolism (butyrate, $\beta$-hydroxybutyrate, glutamine, glucose). Generally, the effect of acute fasting on substrate oxidation was greater than that of chronic malnutrition. ${ }^{11}$

These and other findings show that butyrate is the preferred fuel for colonic epithelial cells, accounting for about $70 \%$ of total energy consumption. The colonic mucosa may be especially vulnerable during starvation and malnutrition, as luminal fuels make such a great contribution to energy metabolism. The hypothesis has been put forward that a lack of luminal nutrients may impair the morphology (atrophy, colitis) and function (sodium absorption, gut barrier) of colonic epithelial cells.

\section{Effect of SCFAs on mucosal blood flow}

In a denervated autoperfused dog colon preparation, a combination of SCFAs (acetate $75 \mathrm{mM}$, propionate $30 \mathrm{mM}$, butyrate $30 \mathrm{mM}$, instilled in the colonic lumen) increased colonic blood flow and oxygen uptake. Of the three acids, only acetate $(75 \mathrm{mM})$ could mimic the effects of the entire mixture on colonic haemodynamics. ${ }^{12}$ In colonic resection specimens obtained from patients having surgery for cancer, SCFAs dilated microdissected resistance arteries in a concentration dependent manner $(0 \cdot 1-30 \mathrm{mM})$. The effect of acetate was most pronounced, whereas glutamine, a trophic factor in the small gut, did not relax isolated colonic resistance arteries. ${ }^{13}$

These data suggest that SCFAs, especially acetate, may have a trophic effect on the colonic epithelium not only by local action, but also by increasing mucosal blood flow. After transport across the colonic mucosa to the portal circulation, acetate alone passes the liver and is recovered in peripheral blood. ${ }^{14}$ It is, therefore, also recirculated to the splanchnic vessels and may relax resistance arteries.

Effect of SCFAs on ileocolonic motility

SCFAs at concentrations occurring physiologically in the canine colon stimulated motility of isolated ileal loops. The effect of acetate on ileal contractions exceeded that of a mixed SCFA solution. Propionate or butyrate, when tested singularly, did not augment motility. ${ }^{15}$ In healthy volunteers intubated with multilumen catheters, a mixture of SCFAs (concentrations similar to those of colonic contents) instilled into the ileum produced more motor events than air or saline. ${ }^{16}$ SCFAs also stimulated the colonic motility in vivo in the rat: propionate, n-butyrate, and n-valerate increased the contractile response of middle and distal, but not proximal, segments of the colon. ${ }^{17}$

SCFAs have thus been shown to be associated with a motor response to coloileal reflux and may be regarded as components of a chemical reflux barrier. Their effect on the motility of various colonic segments is not well understood at present.

\section{Effects of SCFAs on mucus release and cellular differentiation}

Infusion of SCFAs into the isolated rat caecum decreased the number of PAS (periodic acid Schiff reaction) positive cells, but was without effect in the more distal colon. ${ }^{18}$ SCFAs, therefore, decrease the number of mucus storing cells, presumably by a local mechanism. Mucus released from these cells seems to contribute to a mucus layer between the luminal contents and the mucosa. This layer provides a microclimate, which differs from the luminal bulk phase in its physicochemical properties. This microclimate is $\mathrm{pH}$ constant and may play an important part in the absorption of protonated SCFAs. ${ }^{6}$

Differentiation and proliferation of the colonic mucosa are reviewed together as these two factors are interdependent. The immature dividing colonocytes are located in the lower $60 \%$ of the colonic crypts. After division, cells migrate up the crypt toward the surface and become mature in function. They become highly polarised and develop a complex cytoskeleton. Their brush border expresses hydrolases, such as alkaline phosphatase or sucrase. SCFAs and especially butyrate do not seem to further differentiate normal colonic mucosa, probably because a state of full differentiation has already been attained. ${ }^{19}$

The effects of butyrate on biological behaviour differ considerably between normal and neoplastic cells. Butyrate is a strong differentiating (and anti-proliferative) agent for various human colon cancer cell lines in vitro. ${ }^{20}$ At concentrations of $1-5 \mathrm{mmol} / 1$ it causes cancer cells to acquire a phenotype more consistent with normal cells. ${ }^{21}$ It restores the cytoskeleton and the composition of the glycosylated cell surface components. ${ }^{22}$ Furthermore, butyrate induces the expression of hydrolases and storage of glycogen. ${ }^{23}$ On a molecular level, butyrate induces hyperacetylation of histones and modifies oncogene expression (for example, down regulation of $\mathrm{N}$-ras). ${ }^{24}$ There are many published works on the role of butyrate in carcinogenesis, which exceeds the scope of this paper (for review, see ref 19, 24). 


\section{Effects of SCFAs on intestinal cell proliferation}

In many animal studies the feeding of dietary fibre or starch stimulated colonic cell proliferation. ${ }^{25}$ This effect was absent in germ free rats showing that bacterial carbohydrate fermentation was necessary as a factor in raising cell turnover. ${ }^{26}$ SCFAs - that is, end products of fermentation - were subsequently identified as the causative agents: the infusion of SCFAs into the rat colon raised parameters of mucosal cellularity (mucosal weight, protein, RNA, DNA) significantly. The magnitude of effect was similar with butyrate alone as with a combination of SCFAs (acetate+ propionate+ butyrate). ${ }^{27}$ In vitro studies with normal human caecal biopsy specimens showed that SCFAs stimulated cell proliferation in the basal $60 \%$ of the crypts - that is, the physiological proliferative compartment: butyrate (10 $\mathrm{mmol} / \mathrm{l})$, propionate $(25 \mathrm{mmol} / \mathrm{l})$, and the SCFA mixture (acetate $60 \mathrm{mmol} / \mathrm{l}$, propionate $25 \mathrm{mmol} / \mathrm{l}$, butyrate $10 \mathrm{mmol} / \mathrm{l}$ ) had a similar effect on DNA labelling, while the effect of acetate $(60 \mathrm{mmol} / \mathrm{l})$ was significantly smaller. ${ }^{28}$

Thus, there is evidence that SCFAs have a trophic effect on the normal colonic mucosa. This may be important in relation to parenteral and enteral nutrition as there are data that mucosal atrophy occurs after a few days of bowel rest. ${ }^{29}$ To avoid epithelial atrophy and, possibly, bacterial translocation from the gut lumen to the circulation, the addition of fermentable fibre to liquid formula diets may be helpful. ${ }^{30}$

\section{SCFAs in experimental postoperative conditions}

Increasing evidence that the colonic mucosa preferentially uses SCFAs as respiratory fuels has prompted investigators to study the possible effects of intracolonic SCFA infusions on the injured colon. In a rat model, transection and anastomosis of the descending colon was performed, and SCFAs were infused through a catheter placed proximal to the anastomosis. The anastomotic bursting pressure was significantly higher in animals receiving a SCFA mixture (acetate+propionate+butyrate) than in the control group (electrolyte infusion). ${ }^{31}$ In a rat model of the short bowel syndrome (80\% small bowel resection) the addition of pectin (a non-starch polysaccharide degraded to SCFA in the colon) to a fibre free chemically defined elemental diet increased parameters of mucosal cellularity (mucosal mass, DNA, RNA, and protein content) in the remaining ileum and colon. This was associated with a diminished weight loss compared with control animals fed the same diet without added pectin. ${ }^{32}$ In the same model, supplementation of total parenteral nutrition with SCFAs increased mucosal weight and DNA content in the jejunum and ileum without affecting nutritional parameters (body weight, nitrogen balance). There was, however, no significant effect of added SCFAs on the colonic mucosal parameters. ${ }^{33}$

\section{SCFAs and colitis}

The hypothesis has been put forward that a lack of luminal SCFAs leads, in the short term, to mucosal atrophy and, in the long term, to 'nutritional colitis'. 4 This is especially evident in diversion colitis, which develops after complete diversion of the faecal stream and subsides after restoration of colorectal continuity. ${ }^{34}$ In four patients with diversion colitis SCFA irrigation (acetate 60 , propionate 30 , and butyrate $40 \mathrm{mmol} / \mathrm{l}$ ) for two to three weeks resulted in macroscopic and histological resolution of inflammation. ${ }^{35}$ As decreased faecal concentrations of SCFAs have also been shown to occur in patients with ulcerative colitis $^{36}$ SCFA enemas have been used to treat acute distal inflammation. Rectal irrigation with a SCFA mixture was effective in reducing the degree of inflammation after a six week treatment period (uncontrolled trial). ${ }^{37}$ In another placebo controlled study butyrate enemas $(100 \mathrm{mmol} / \mathrm{l})$ were used instead of the SCFA mixture, because the evidence was strongest for butyrate to affect the colonic mucosa ${ }^{3}$ : after two weeks of treatment butyrate ameliorated acute inflammation judged by macroscopic and histological criteria, whereas no change was seen under placebo conditions. ${ }^{38}$

1 Windmueller HG, Spaeth AE. Identification of ketone bodies and glutamine as the major respiratory fuels in vivo for postabsorptive rat small intestine. $\mathscr{f}$ Biol Chem 1978; 253: postabs $69-76$.

2 Souba WW, Herskowitz K, Austgen TR, et al. Glutamine nutrition: theoretical considerations and therapeutic impact. FPEN 1990; 14: 237-43S.

3 Roediger WEW. Role of anaerobic bacteria in the metabolic welfare of the colonic mucosa in man. Gut 1980; 21: 793-8.

4 Roediger WEW. The starved colon - diminished mucosal nutrition, diminished absorption, and colitis. Dis Colon Rectum 1990; 33: 858-62.

5 Ruppin H, Bar-Meir YS, Soergel KH, et al. Absorption of short-chain fatty acids by the colon. Gastroenterology 1980; 78: $1500-7$.

6 von Engelhardt W, Busche R, Gros G, et al. Absorption of short-chain fatty acids: mechanisms and regional differences in the large intestine. In: Roche AF, ed. Short-chain ences in the large intestine. In: Roche AF, ed. Short-chain
fatty acids: metabolism and clinical importance. Report of the fatty acids: metabolism and clinical importance. Report of the Ohio: Ross Laboratories, 1991: 60-2.

7 Binder HJ, Metha P. Short-chain fatty acids stimulate active sodium and chloride absorption in vitro in the rat distal colon. Gastroenterology 1989; 96: 989-96.

8 Scheppach W, Sachs M, Bartram P, et al. Faecal short-chain fatty acids after colonic surgery. Eur $f$ Clin Nutr 1989; 43: fatty acid
$21-5$.

9 Clausen MR, Bonnen $\mathrm{H}$, Tvede $\mathrm{M}$, et al. Colonic fermentation to short-chain fatty acids is decreased in antibioticassociated diarrhea. Gastroenterology 1991; 101: $1497-504$.

10 Henning SJ, Hird FJR. Concentrations and metabolism of volatile fatty acids in the fermentative organs of two species of kangaroo and the guinea-pig. Br $\mathscr{f}$ Nutr 1970; 24: $145-55$.

11 Firmansyah A, Penn D, Lebenthal E. Isolated colonocyte metabolism of glucose, glutamine, n-butyrate, and $\beta$-hydroxybutyrate in malnutrition. Gastroenterology 1989; 97: 622-9.

12 Kvietys PR, Granger DN. Effect of volatile fatty acids on blood flow and oxygen uptake by the dog colon. Gastroenterology 1981; 80: 962-9.

13 Mortensen FV, Nielsen H, Mulvany MJ, et al. Short chain fatty acids dilate isolated human colonic resistance arteries. Gut 1990; 31: 1391-4.

14 Scheppach W, Pomare EW, Elia M, et al. The contribution of the large intestine to blood acetate in man. Clin Sci of the large intestine

15 Kamath PS, Hoepfner MT, Phillips SF. Short-chain fatty acids stimulate motility of the canine ileum. Am $\mathcal{f}$ Physiol 1987; 253: G427-33.

16 Kamath PS, Phillips SF, Zinsmeister AR. Short-chain fatty acids stimulate ileal motility in humans. Gastroenterology 1988; 95: 1496-502.

17 Yajima T. Contractile effect of short-chain fatty acids on the isolated colon of the rat. $\mathcal{F}$ Physiol $1985 ; 368: 667-78$.

18 Sakata T. Effects of short-chain fatty acids on epithelial cell proliferation and mucus release in the intestine. In: Roche $\mathrm{AF}$, ed. Short-chain fatty acids: metabolism and clinical 
importance. Report of the Tenth Ross conference on medical research. Columbus, Ohio: Ross Laboratories, 1991: 63-7.

19 Young GP, Gibson P. Contrasting effects of butyrate on proliferation and differentiation of normal and neoplastic cells. In: Roche AF, ed. Short-chain fatty acids: metabolism and clinical importance. Report of the Tenth Ross conference on medical research. Columbus, Ohio: Ross Laboratories, 1991: 50-5.

20 Tanaka Y, Bush KK, Klauck TM, et al. Enhancement of butyrate-induced differentiation of HT-29 human colon carcinoma cells by 1,25 -dihydroxyvitamin $\mathrm{D}_{3}$. Biochem Pharmacol 1989; 38: 3859-65.

21 Niles RM, Wilhelm SA, Thomas $\mathrm{P}$, et al. The effect of sodium butyrate and retinoic acid on growth and CEA production in a series of human colorectal tumor cell lines representing different states of differentiation. Cancer Invest 1988; 6: 39-45

22 Siddiqui B, Kim YS. Effects of sodium butyrate, dimethyl sulfoxide, and retinoic acid on glycolipids of human adenocarcinoma cells. Cancer Res 1984; 44: 1648-52.

23 Dexter DL, Lev R, McKendall GR, et al. Sodium-butyrate induced alteration of growth properties and glycogen levels in cultured human colon carcinoma cells. Histochem F 1984; 16: 137-49.

24 Kruh J, Defer N, Tichonicky L. Molecular and cellular effects of sodium butyrate. In: Roche AF, ed. Short-chain fatty acids: metabolism and clinical importance. Report of the Tenth Ross conference on medical research. Columbus, Ohio: Ross Laboratories, 1991: 45-50.

25 Lupton JR, Coder DM, Jacobs LR. Long-term effects of fermentable fibers on rat colonic $\mathrm{pH}$ and epithelial cell cycle. $\mathcal{F}$ Nutr 1988; 118: 840-5.

26 Goodlad RA, Ratcliffe B, Fordham JP, et al. Does dietary fibre stimulate intestinal epithelial cell proliferation in germ free rats? Gut 1989; 30: 820-5.
27 Kripke SA, Fox AD, Berman JM, et al. Stimulation of intestinal mucosal growth with intracolonic infusion of short-chain fatty acids. FPEN 1989; 13: 109-16.

28 Scheppach W, Bartram P, Richter A, et al. Effect of shortchain fatty acids on the human colonic mucosa in vitro. FPEN 1992; 16: 43-8.

29 Ryan GP, Dudrick SJ, Copeland EM, et al. Effects of various diets on colonic growth in rats. Gastroenterology $1979 ; 77: 658-63$.

30 Scheppach W, Burghardt W, Bartram P, et al. Addition of dietary fiber to liquid formula diets: the pros and cons. IPEN 1990; 14: 204-9.

31 Rolandelli RH, Koruda MJ, Settle RG, et al. Effects of intraluminal infusion of short-chain fatty acids on the healing of colonic anastomosis in the rat. Surgery 1986;100: 198-203.

32 Koruda MJ, Rolandelli RH, Settle RG, et al. The effect of pectin-supplemented elemental diet on intestinal adaptapectin-supplemented elemental diet on intestinal adaptation to mas 340 .

33 Koruda MJ, Rolandelli RH, Settle RG, et al. Effect of parenteral nutrition supplemented with short-chain fatty acids on adaptation to massive small bowel resection. Gastroenterology 1988; 95: 715-20.

34 Glotzer DJ, Glick ME, Goldman H. Proctitis and colitis folowing diversion of the fecal stream. Gastroenterology 1981; 80: 438-41.

35 Harig JM, Soergel KH, Komorowski RA, et al. Treatment of diversion colitis with short-chain fatty acid irrigation. N Engl 7 Med 1989; 320: 23-8.

36 Vernia P, Gnaedinger A, Hauck W, et al. Organic anions and the diarrhea of inflammatory bowel disease. Dig Dis Sci 1988; 33: 1353-8.

37 Breuer RI, Buto SK, Christ ML, et al. Rectal irrigation with short-chain fatty acids for distal ulcerative colitis. Preliminary report. Dig Dis Sci 1991; 36: 185-7.

38 Scheppach W, Sommer H, Kirchner T, et al. Effect of butyrate enemas on the colonic mucosa in distal ulcerative colitis. Gastroenterology 1992; 103: 51-6. 